\title{
The serum CXCL13 level is associated with the Glasgow Prognostic Score in extranodal NK/T-cell lymphoma patients
}

\author{
Seok Jin Kim ${ }^{1,5}$, Kyung Ju Ryu ${ }^{2}$, Mineui Hong ${ }^{3}$, Young Hyeh Ko ${ }^{4}$ and Won Seog Kim ${ }^{\text {* }}$
}

\begin{abstract}
Background: The Glasgow Prognostic Score (GPS) measures inflammation and proves its prognostic value in patients with extranodal natural killer (NK)/T-cell lymphoma (ENKTL) which is commonly combined with inflammatory lesion. Given inflammatory chemokines play an important role in tumor progression, we hypothesized that chemokines might influence ENKTL aggressiveness through interaction with their receptors in the tumor tissue.

Methods: We measured the serum levels of C-X-C motif ligand 13 (CXCL13) in 69 patients with ENKTL who received non-anthracycline-based chemotherapy and/or concurrent chemoradiotherapy because CXCL13 is thought to have a pro-tumor effect through interaction with its receptor, the C-X-C chemokine receptor 5 (CXCR5). We analyzed the association of serum CXCL13 with the GPS, and their prognostic relevance. The levels of CXCL13 were measured using a multiplex chemokine assay on archived frozen serum samples.
\end{abstract}

Results: Patients were categorized into high and low CXCL13 groups if they had CXCL13 levels above or below the median value of $29.1 \mathrm{pg} / \mathrm{mL}$, respectively. The high CXCL13 group and grouping by the GPS showed a significant association with poor progression-free survival. The elevated serum levels of CXCL13 were also significantly associated with a high score of the GPS. High CXCL13 levels and GPS were significantly associated with high tumor burden predicting poor prognosis including stages III/IV, extranasal presentation, bone marrow invasion, and presence of Epstein-Barr virus (EBV) DNA in blood. Furthermore, serum CXCL13 and GPS discriminated patients at risk of treatment failure among patients with low tumor burden (stage I/II) and non-detectable EBV DNA.

Conclusions: Serum levels of CXCL13 were associated with the prognostic value of GPS. Grouping by the serum CXCL13 might predict survival outcomes in patients with ENKTL, suggesting that it is a potential therapeutic target.

Keywords: Extranodal NK/T-cell lymphoma, Inflammation, Chemokine, CXCL13, GPS

\section{Background}

Extranodal natural killer (NK)/T-cell lymphoma (ENKTL) is a subtype of non-Hodgkin lymphoma (NHL), and ENKTL is strongly associated with latent Epstein-Barr virus (EBV) infection and usually shows aggressive behavior with a poor prognosis [1]. Although chemoradiotherapy and non-anthracycline-based chemotherapy have been shown to improve outcome [2,3], treatment failures occur in patients with any stage of disease. Identifying a prognostic indicator might allow the identification of patients who are at

\footnotetext{
*Correspondence: wskimsmc@skku.edu

'Division of Hematology and Oncology, Department of Medicine, Samsung Medical Center, Sungkyunkwan University School of Medicine, Seoul, Korea
} Full list of author information is available at the end of the article risk of poor treatment outcomes. A recent study demonstrated that the Glasgow Prognostic Score (GPS) has prognostic value in ENKTL [4]. The GPS score is based on measures of C-reactive protein (CRP) and albumin and therefore reflects inflammatory activity [5]. Given that GPS reflects both inflammation and ENKTL prognosis, tumor aggressiveness may be associated with higher states of inflammation. Inflammatory cells frequently infiltrate ENKTL tumors, and the majority of patients have clinical signs of inflammation such as nasal tract inflammation. However, any underlying mechanism by which inflammation may contribute to poor ENKTL prognosis is still unknown.

The inflammatory milieu of a tumor's microenvironment is important in its growth and progression [6,7]. 
Therefore, we hypothesized that chemokines might influence ENKTL aggressiveness through interaction with their receptors in the tumor tissue. Chemokines are a family of small signaling cytokines that recruit leukocytes to inflammatory sites and play a role in homeostatic activities (including subsequent lymphocyte migration) $[8,9]$. On the other hand, chemokines also contribute to tumor development, growth, and metastasis $[10,11]$. Among various chemokines, C-X-C motif ligand 13 (CXCL13, also named as B-cell attracting chemokine 1 (BCA-1)) is thought to play an important pro-tumor role in colon, prostate, and breast cancers through the interaction with its receptor, the C-X$\mathrm{C}$ chemokine receptor 5 (CXCR5) [12-14]. In particular, a recent in vitro study with colorectal cancer cell lines reported the interaction of CXCL13 with CXCR5 activated the phosphatidylinositol-3 kinase (PI3K)/AKT pathway leading to migration and invasion of cancer cells [15]. In $\mathrm{NHL}$, a recent prospective study of inflammatory markers demonstrated a significant association of serum CXCL13 with the risk of lymphoma supporting its role in the lymphoma development [16]. Thus, considering its association with lymphoma and the activation of PI3K/AKT pathway, CXCL13 might have a positive correlation with the aggressiveness of ENKTL because latent membrane protein 1, an EBV oncoprotein could activate the PI3K/ AKT pathway in ENKTL [17]. If so, the elevated serum level of CXCL13 could be an underlying mechanism for the prognostic value of GPS in patients with ENKTL.

Table 1 Clinical patient characteristics and their association with survival outcomes

\begin{tabular}{|c|c|c|c|c|c|c|c|}
\hline \multirow{2}{*}{ Characteristics } & & \multirow[b]{2}{*}{$n$} & \multirow[b]{2}{*}{$\%$} & \multicolumn{2}{|l|}{ PFS } & \multicolumn{2}{|l|}{ OS } \\
\hline & & & & HR & $P$ & HR & $P$ \\
\hline \multirow[t]{2}{*}{ Age (years) } & $\leq 60$ & 56 & 81 & & & & \\
\hline & $>60$ & 13 & 19 & 2.164 & 0.039 & 2.489 & 0.024 \\
\hline \multirow[t]{2}{*}{ Sex } & Male & 46 & 33 & & & & \\
\hline & Female & 23 & 67 & 1.215 & 0.575 & 0.752 & 0.494 \\
\hline \multirow[t]{2}{*}{ Performance status } & ECOG 0/1 & 56 & 81 & & & & \\
\hline & $\mathrm{ECOG} \geq 2$ & 13 & 19 & 4.372 & $<0.001$ & 3.736 & 0.001 \\
\hline \multirow[t]{2}{*}{ Ann Arbor stage } & $|/| \mid$ & $29 / 11$ & $42 / 16$ & & & & \\
\hline & III/IV & $5 / 24$ & $7 / 35$ & 1.935 & $<0.001$ & 1.898 & $<0.001$ \\
\hline \multirow[t]{2}{*}{ Serum LD } & Normal & 30 & 44 & & & & \\
\hline & Increased & 39 & 56 & 3.124 & 0.002 & 2.456 & 0.026 \\
\hline \multirow[t]{2}{*}{ B symptoms } & Absence & 39 & 56 & & & & \\
\hline & Presence & 30 & 44 & 2.634 & 0.004 & 2.310 & 0.027 \\
\hline \multirow[t]{2}{*}{ LN involvement } & Absence & 40 & 58 & & & & \\
\hline & Presence & 29 & 42 & 2.236 & 0.017 & 3.258 & 0.002 \\
\hline \multirow[t]{2}{*}{ Primary site } & Nasal & 41 & 59 & & & & \\
\hline & Extranasal & 28 & 41 & 4.092 & $<0.001$ & 4.240 & $<0.001$ \\
\hline \multirow[t]{2}{*}{ Bone marrow invasion } & No & 56 & 81 & & & & \\
\hline & Yes & 13 & 19 & 6.591 & $<0.001$ & 5.298 & $<0.001$ \\
\hline \multirow[t]{2}{*}{ Extranodal involvement } & $0 / 1$ & 43 & 62 & & & & \\
\hline & $\geq 2$ & 26 & 38 & 2.948 & 0.001 & 2.616 & 0.011 \\
\hline \multirow[t]{2}{*}{ EBV DNA } & Non-detectable & 42 & 61 & & & & \\
\hline & Detectable & 27 & 39 & 4.111 & $<0.001$ & 3.482 & $<0.001$ \\
\hline \multirow[t]{2}{*}{$|P|$} & Low/low-intermediate & $33 / 11$ & $48 / 16$ & & & & \\
\hline & High-intermediate/High & $17 / 8$ & $24 / 12$ & 2.482 & $<0.001$ & 2.031 & $<0.001$ \\
\hline \multirow[t]{2}{*}{ NKPI } & Group I/II & $18 / 8$ & $26 / 12$ & & & & \\
\hline & Group III/IV & $20 / 23$ & $29 / 33$ & 2.162 & $<0.001$ & 2.036 & 0.001 \\
\hline \multirow[t]{3}{*}{ GPS } & 0 & 32 & 46 & & & & \\
\hline & 1 & 22 & 32 & & & & \\
\hline & 2 & 15 & 22 & 2.660 & $<0.001$ & 3.052 & $<0.001$ \\
\hline
\end{tabular}


Therefore, we measured the serum levels of CXCL13 and analyzed their correlation with the GPS and survival outcomes of ENKTL patients.

\section{Patients and methods Patients}

Patients diagnosed with ENKTL from two prospective cohort studies between September 2008 and December 2012 (first study: 2008-2011, NCT\#00822731; second ongoing study since 2012, NCT\#01877109) were included in this study. Written informed consent was obtained from all patients. Clinical information, laboratory results, and serum samples at diagnosis were obtained from the cohort studies. All patients had received treatment with curative intent. Treatments included concurrent chemoradiotherapy (CCRT) followed by systemic chemotherapy for stage IE or IIE as previously reported $[2,18]$ or systemic chemotherapy with SMILE (steroid, methotrexate, ifosfamide, L-asparaginase, and etoposide) for stage III/IV $[19,20]$. The primary tumor site was determined based on the clinical presentation and included nasal and extranasal sites, such as the skin, soft tissue, and other organs. Three comprehensive prognostic models including International Prognostic Index (IPI), NK Prognostic Index (NKPI), and GPS were used to determine risk group stratification. The GPS was calculated according to serum CRP and albumin levels that were measured as part of the clinical practice at diagnosis as described previously [5,21]. Thus, patients with both an elevated CRP level $(>10 \mathrm{mg} / \mathrm{L})$ and hypoalbuminemia $(<35 \mathrm{~g} / \mathrm{L})$ received a score of 2 whereas patients with elevated CRP or hypoalbuminemia were allocated a score of 1 . Patients with neither of these abnormalities were given a score of 0 . The EBV DNA titer was measured upon diagnosis from a whole blood sample, as previously reported [22]. The patients were dichotomized according to positive and negative EBV DNA. Survival status was updated at the time of analysis in December 2014. This study
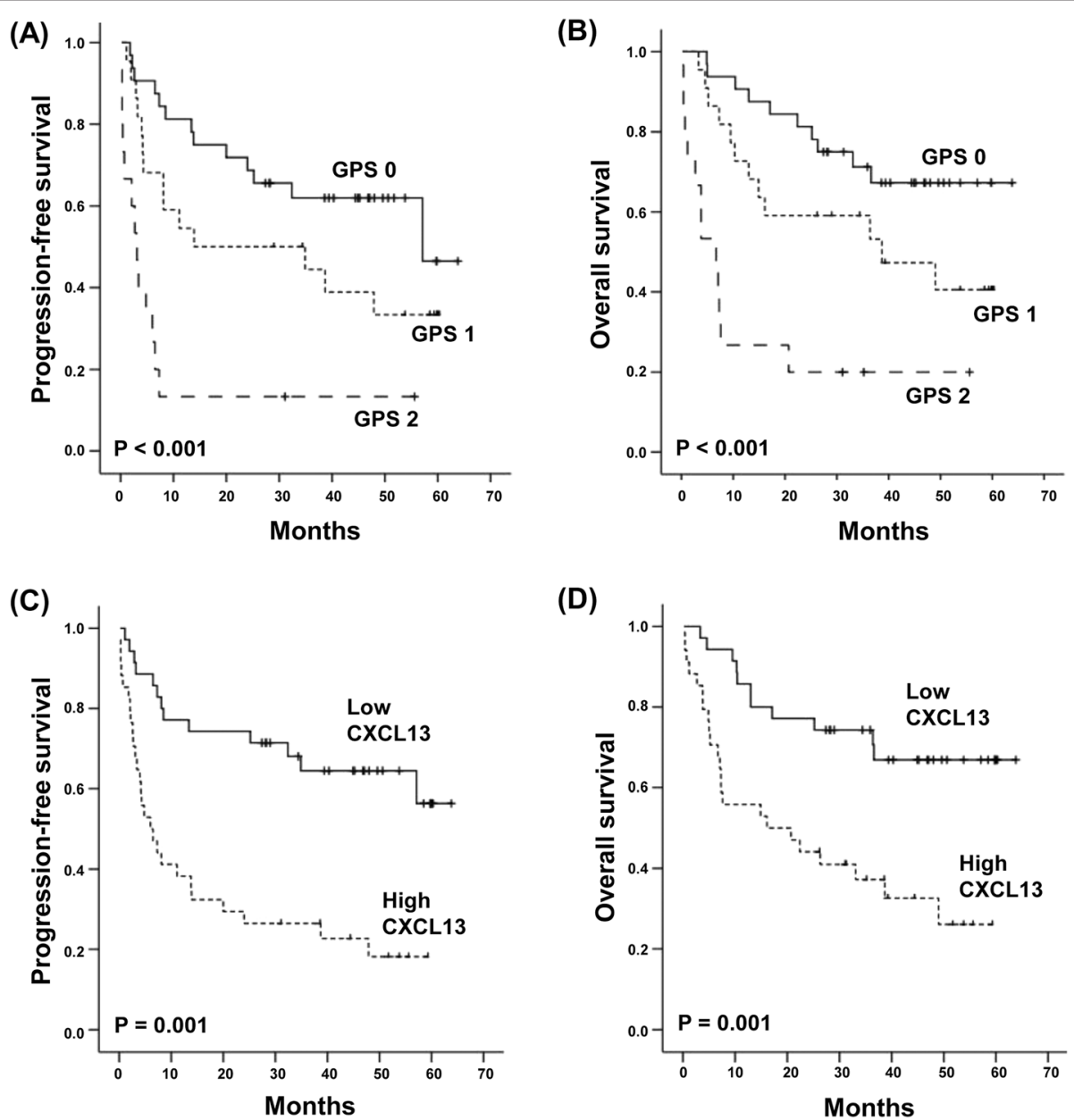

(D)

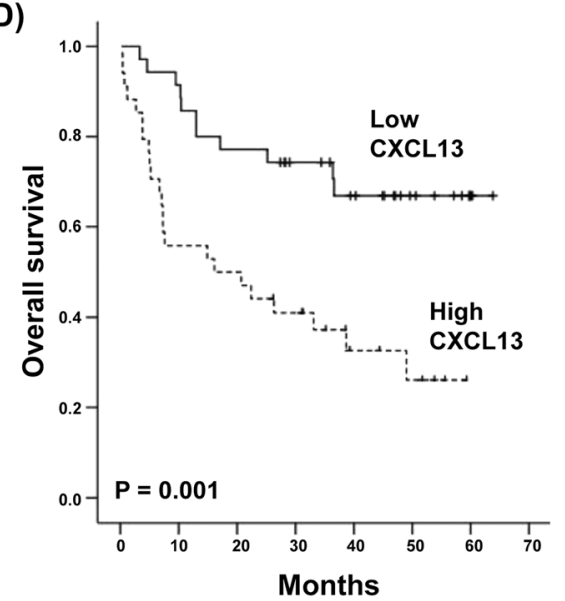

Figure 1 The association of overall and progression-free survival with GPS and serum CXCL13. (A, B) Grouping by the GPS demonstrates a significant association with OS and PFS. (C, D) High CXCL13 levels are more significantly associated with shorter overall and progression-free survival than are lower levels. 
was approved by the Institutional Review Board of the Samsung Medical Center.

\section{Measurement of serum CXCL13 and CXCL13/CXCR5 immunohistochemistry}

Serum samples were collected at diagnosis and stored at $-80^{\circ} \mathrm{C}$ until analysis. A Procarta cytokine profiling kit (Panomics, CA, USA) was used to measure CXCL13 levels (three times) according to the manufacturer's instructions. In order to evaluate the tissue expression of CXCL13 and CXCR5, immunohistochemical analysis was performed on formalin-fixed, paraffin-embedded, $4-\mu \mathrm{m}$ thick tissue sections. The tissue sections were deparaffinized three times in xylene for a total of $15 \mathrm{~min}$ and were then incubated with the primary monoclonal antibody against CXCL13 (Clone 53610; MAB801; R\&D Systems, Minneapolis, MN, USA), and CXCR5 (Clone 51505; FAB190P; R\&D Systems, Minneapolis, MN, USA). Immunostaining was performed using a BOND-MAX autoimmunostainer
(Leica Microsystems, Wetzlar, Germany) with BOND Polymer Refine Detection (DS9800; Vision BioSystems, Melbourne, Australia). Positivity for CXCL13 and CXCR5 was determined by comparing to the normal positive control from the tonsillar germinal center. In every staining set, a negative control was included in which the primary antibodies and probes were omitted.

\section{Statistics}

The chi-square test was used to analyze the association between serum CXCL13 with clinical and laboratory parameters. The Kaplan-Meier method was used for univariate analysis of survival outcomes. The survival outcomes were compared with the log-rank test. Progression-free survival (PFS) was defined as the time from the date of diagnosis to the date of documented disease progression or death. In contrast, the overall survival (OS) was measured from the date of diagnosis to the date of death due to any cause. The OS was censored at the date of

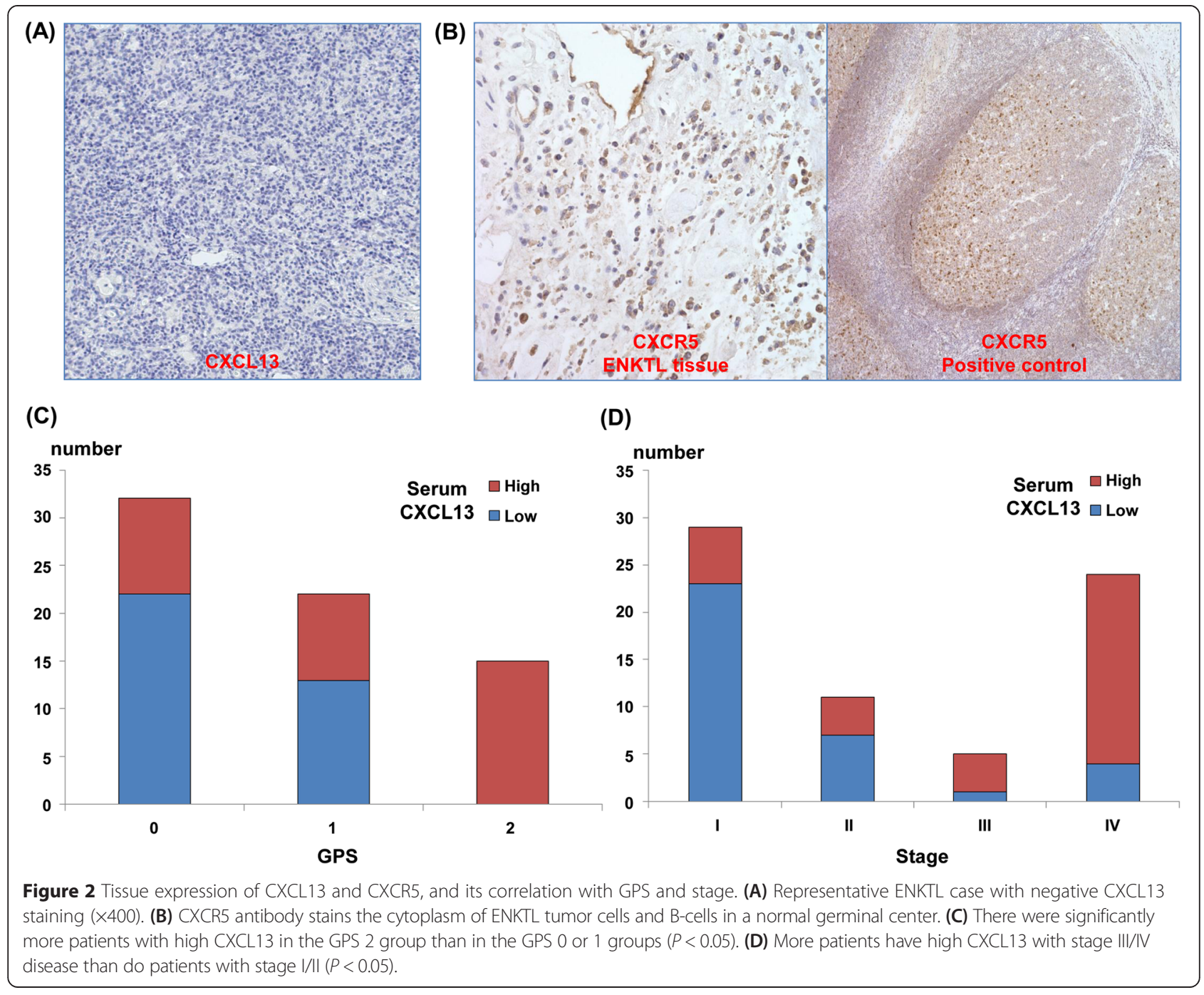


the last follow-up visit. Cox regression hazard analysis was used in multivariate analysis for survival outcomes. A two-sided $P$ value $<0.05$ was considered statistically significant.

\section{Results}

\section{Characteristics of patients}

We analyzed 69 patients with a median age of 48 years at diagnosis (range 17-75 years). Forty patients (58\%) had stages I or II, while 29 patients had stages III or IV (42\%). The most common primary tumor site was the nasal tract $(n=41)$. Twenty-eight patients had extranasal disease in areas including the skin and gastrointestinal tract (Table 1). A circulating EBV DNA level was detected in the whole blood of 27 patients, while 42 patients had no detectable EBV DNA. The majority of patients $(n=44,64 \%)$ were classified as being at low or low-intermediate risk based on the IPI. Forty-three patients $(62 \%)$ were classified into groups III or IV based on their NKPI [23,24]. The median potential follow-up was 47 months. A total of 38 patients had relapse or progression. Thirty-four patients died, including two cases of non-disease-related death. Univariate analysis of the survival outcomes demonstrated that all clinical parameters (except sex) were significantly associated with OS and PFS (Table 1). The GPS also demonstrated prognostic relevance to OS and PFS in ENKTL patients, as previously reported (Figure 1A, B) [4].

\section{Serum CXCL13 and the GPS}

The mean value of CXCL13 was $155.2 \mathrm{pg} / \mathrm{mL}$ (standard deviation (SD): $406.7 \mathrm{pg} / \mathrm{mL}$ ). There was only one patient with an undetectable CXCL13 level. The median value was $29.1 \mathrm{pg} / \mathrm{mL}$ (range: $0.0-2517.6 \mathrm{pg} / \mathrm{mL}$ ). Patients were categorized into high (CXCL13 level $>$ median value, $n=34)$ and low (CXCL13 level $\leq$ median value, $n=35$ ) CXCL13 groups. The high CXCL13 group had a higher frequency of PFS events (27/34, 79\%), including relapse/ progression or death, than did the low CXCL13 group (13/35, 37\%). Therefore, high levels of CXCL13 were significantly associated with worse OS and PFS (Figure 1C, D). Immunohistochemical staining for CXCL13 from 30 patients revealed that all of the tumor cells were negative for CXCL13 (Figure 2A). The expression of CXCL13 was also

Table 2 The association of CXCL13 and CCL3 with unfavorable parameters

\begin{tabular}{|c|c|c|c|c|c|c|c|}
\hline \multirow[b]{2}{*}{ Characteristics } & & \multicolumn{3}{|c|}{ CXCL13 } & \multicolumn{3}{|c|}{ GPS } \\
\hline & & Low & High & $P$ & $0 / 1$ & 2 & $P$ \\
\hline \multirow[t]{2}{*}{ Age (years) } & $\leq 60$ & 32 & 24 & & 48 & 8 & \\
\hline & $>60$ & 3 & 10 & 0.034 & 6 & 7 & 0.005 \\
\hline \multirow[t]{2}{*}{ Ann Arbor stage } & $|/| \mid$ & 30 & 10 & & 37 & 3 & \\
\hline & III/IV & 5 & 24 & $<0.001$ & 17 & 12 & 0.001 \\
\hline \multirow[t]{2}{*}{ Serum LDH } & Normal & 22 & 8 & & 28 & 2 & \\
\hline & Increased & 13 & 26 & 0.001 & 26 & 13 & 0.009 \\
\hline \multirow[t]{2}{*}{ B symptoms } & Absence & 25 & 14 & & 35 & 4 & \\
\hline & Presence & 10 & 20 & 0.015 & 19 & 11 & 0.017 \\
\hline \multirow[t]{2}{*}{ LN involvement } & Absence & 25 & 15 & & 36 & 4 & \\
\hline & Presence & 10 & 19 & 0.029 & 18 & 11 & 0.008 \\
\hline \multirow[t]{2}{*}{ Primary site } & Nasal & 29 & 12 & & 38 & 3 & \\
\hline & Extranasal & 6 & 22 & $<0.001$ & 16 & 12 & 0.001 \\
\hline \multirow[t]{2}{*}{ Bone marrow invasion } & No & 33 & 23 & & 49 & 7 & \\
\hline & Yes & 2 & 11 & 0.006 & 5 & 8 & 0.001 \\
\hline \multirow[t]{2}{*}{ Extranodal involvement } & $0 / 1$ & 29 & 14 & & 38 & 5 & \\
\hline & $\geq 2$ & 6 & 20 & $<0.001$ & 16 & 10 & 0.015 \\
\hline \multirow[t]{2}{*}{ EBV DNA } & Non-detectable & 29 & 13 & & 38 & 4 & \\
\hline & Detectable & 6 & 21 & $<0.001$ & 16 & 11 & 0.006 \\
\hline \multirow[t]{2}{*}{$|P|$} & L/LI & 30 & 14 & & 42 & 2 & \\
\hline & $\mathrm{HI} / \mathrm{H}$ & 5 & 20 & $<0.001$ & 12 & 13 & $<0.001$ \\
\hline \multirow[t]{2}{*}{ NKPI } & Group I/II & 22 & 4 & & 24 & 2 & \\
\hline & Group III/IV & 13 & 30 & $<0.001$ & 30 & 13 & 0.036 \\
\hline
\end{tabular}


negative in stromal cells of the tumor tissue although normal lymphocytes adjacent tumor tissue showed positive expression of CXCL13. In contrast, the tumor cells did express CXCR5 (Figure 2B). The serum CXCL13 was significantly associated with risk stratification by the GPS. In particular, all patients from the GPS 2 group had serum levels of CXCL13 that are higher than the median value $(P<0.001$, Figure $2 C)$. The mean serum level from the GPS 2 group $2(505.5 \pm 778.3 \mathrm{pg} / \mathrm{mL})$ was significantly higher than that of the GPS $0(50.2 \pm 74.3 \mathrm{pg} / \mathrm{mL})$ and GPS $1(69.05 \pm 106.8 \mathrm{pg} / \mathrm{mL})$ groups. High CXCL13 levels were significantly associated with unfavorable prognostic signs including advanced stage (III/IV, Figure 2D), extranasal presentation, bone marrow invasion, and extranodal involvement (Table 2). In addition, patients classified as high-risk by the IPI or NKPI had significantly higher serum levels of CXCL13 than did those at lower risk $(P<0.001)$. EBV positivity was also significantly associated with CXCL13 $(P<0.001)$. Like CXCL13, the GPS also showed a significant association with unfavorable parameters and high-risk groups of IPI and NKPI (Table 2).
However, serum levels of CXCL13 and GPS failed to show independent prognostic values for OS and PFS in the multivariate analysis with clinical parameters $(P<0.05$, data not shown).

\section{Subgroup analysis}

As grouping by the serum CXCL13 level and GPS was not independently prognostic for survival outcomes, the subgroup analysis was done according to tumor burden. Patients were dichotomized into high and low tumor burden based on stage and EBV DNA in blood. Elevated CXCL13 levels were associated with poor OS in patients with low tumor burden: those with non-detectable EBV or stages I/II (Figure 3A, B). In contrast, in patients with high tumor burden such as stage III/IV or detectable EBV, the serum CXCL13 was unable to predict prognosis (Figure 3C, D). Grouping by the GPS also showed a significant association with OS in patients with low tumor burden similar to serum CXCL13 level (Figure 4A, B). The association of the GPS with poor OS was less significant in patients with stage III/IV and

\section{(A) Non-detectable EBV}

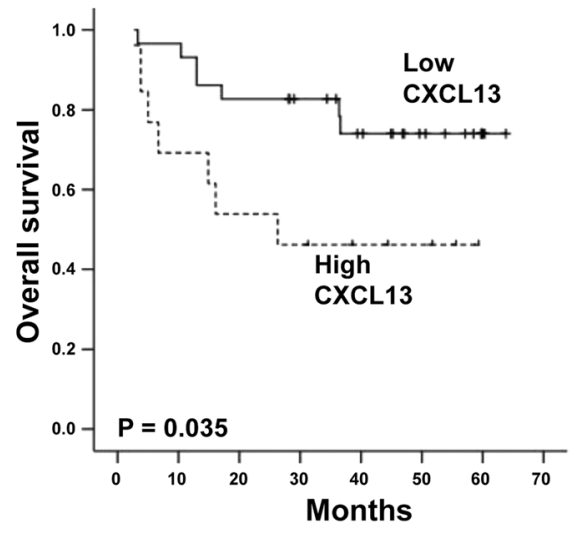

(C) Detectable EBV

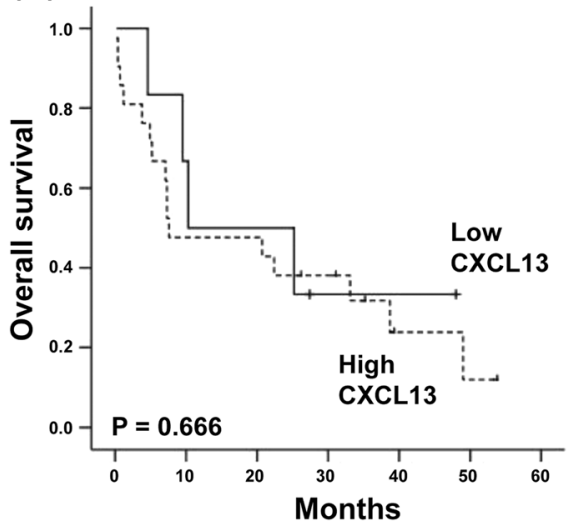

(B) Stage I/II

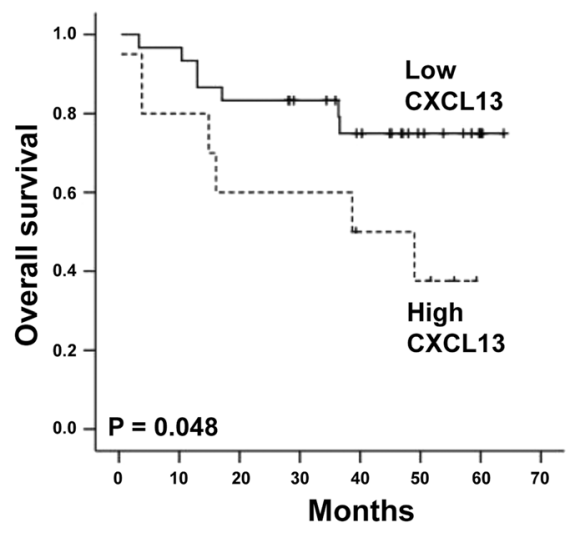

(D) Stage III/IV

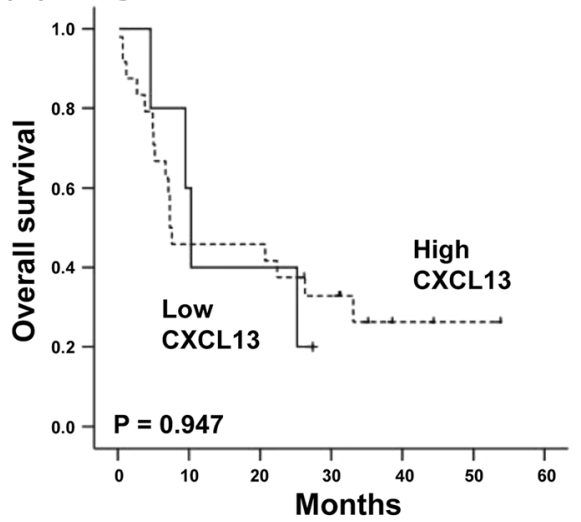

Figure 3 The subgroup analysis for the association of serum CXCL13 with overall survival based on stage and EBV DNA positivity in blood. (A, B) High CXCL13 levels are associated with lower overall survival among patients with non-detectable EBV titers and stage I/II disease. (C, D) CXCL13 fails to predict prognosis in patients with advanced disease and detectable EBV titers. 
(A) Non-detectable EBV

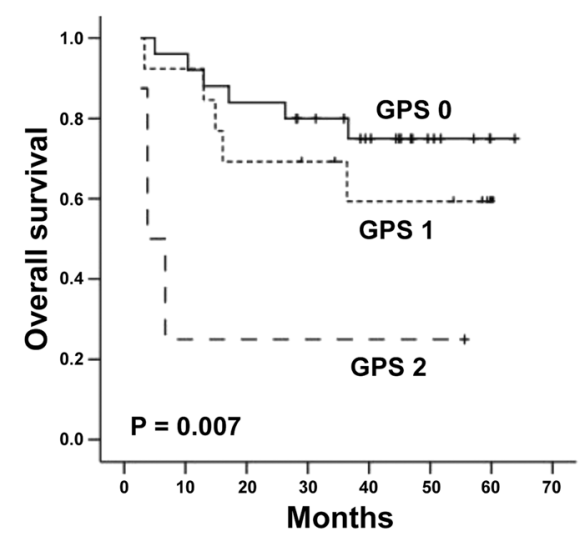

(C) Detectable EBV

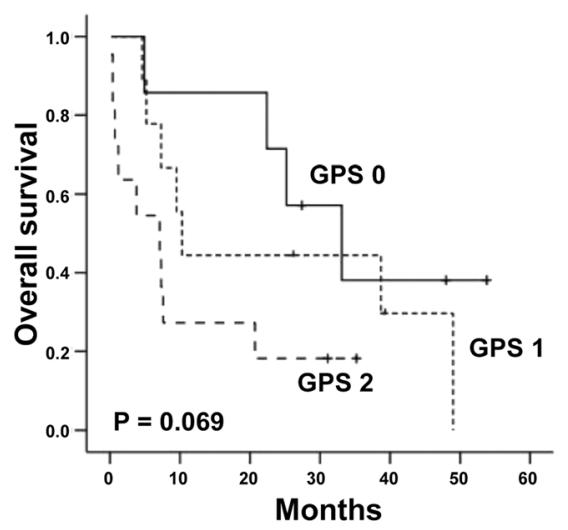

(B) Stage I/II

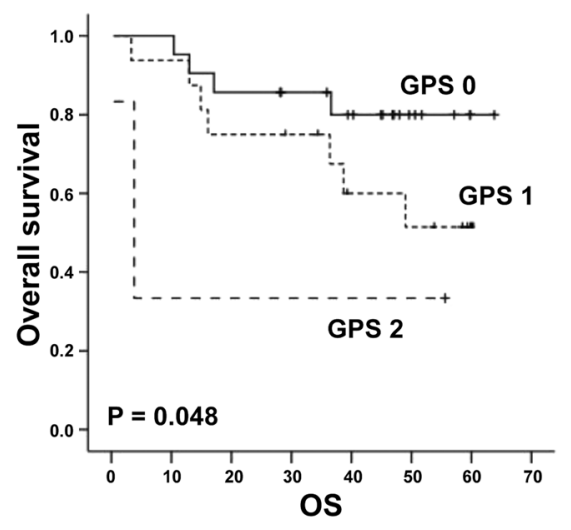

(D) Stage III/IV

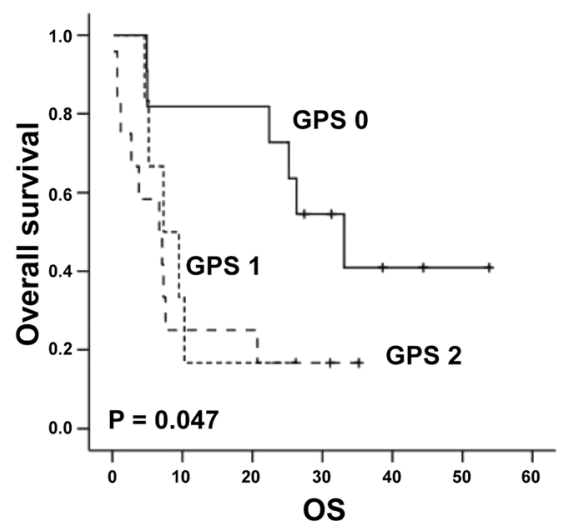

Figure 4 The subgroup analysis for the association of GPS with overall survival based on stage and EBV DNA positivity in blood. (A, B) GPS is associated with lower overall survival among patients with non-detectable EBV titers and stage I/II disease. (C, D) GPS shows a marginal significance in patients with advanced disease and detectable EBV titers.

detectable EBV DNA (Figure 4C, D). The lack of prognostic significance of CXCL13 and GPS in patients with high tumor burden might be related with a strong correlation of elevated CXCL13 and GPS 2 with stage III/IV and detectable EBV in this study (Table 2).

\section{Discussion}

Although a role for inflammation in cancer has long been postulated in the mid-1800s, evidence supporting the association of inflammation with cancer initiation, progression, and mortality has been gathered more recently. The GPS based on CRP and serum albumin reflects the systemic inflammatory response to cancer, and its proven prognostic value in cancer patients augments the contributory role of inflammation to tumor aggressiveness. Our study demonstrated the GPS had a significant association with OS and PFS in ENKTL patients inconsistent with a previous finding [4]. Thus, patients who were given a GPS of 2 showed worse OS and PFS than patients with GPS 0 or 1 (Figure 1A, B). As we hypothesized CXCL13, an inflammatory chemokine might contribute to the prognostic value of GPS, patients with an elevated serum CXCL13 level showed poor survival outcomes (Figure 1C, D). Furthermore, an elevated serum CXCL13 level was strongly correlated with the GPS, especially a score of 2 because all patients with GPS 2 showed an elevated level of CXCL13 (Figure 2C).

CXCL13 is a follicular helper T-cell marker and a known B-cell chemoattractant that plays a role in germinal center formation $[25,26]$. Prior to this study, there was no data about the prognostic value of serum CXCL13 in ENKTL as well as its relation with the GPS. Our study demonstrated a significant association between serum CXCL13 levels and a high-risk ENKTL classification according to the GPS $(P<0.001$, Figure $2 \mathrm{C})$. Thus, our findings suggested the increased serum levels of CXCL13 representing inflammatory activity might be associated with unfavorable characteristics of ENKTL such as tumor burden like previous studies reporting the contribution of CXCL13 to solid tumor progression, that is, [6,7]. The 
immunohistochemistry with tumor tissue showed the positive staining for CXCR5 and negative for CXCL13 on lymphoma cells (Figure 2A, B). This result suggests that the serum CXCL13 might be mostly coming from inflammatory cells, not tumor cells. Although there is no direct data about the interaction of CXCL13 with CXCR5 in lymphoma cells of ENKTL, a previous in vitro study with AIDS-related non-Hodgkin lymphoma cell lines demonstrated migration of lymphoma cells expressing CXCR5 toward CXCL13 [27]. Given that AIDS-related NHL is frequently related with EBV infection, this CXCL13/CXCR5 interaction might be present in ENKTL like AIDS-related NHL. Thus, the association of serum CXCL13 with stage of ENKTL might be influenced by the major contributory effect of CXCL13 to cell migration and invasion. However, further studies are required to clarify the underlying mechanism by which CXCL13/CXCR5 interaction is associated with aggressiveness of ENKTL.

The grouping by serum levels of CXCL13 as well as the GPS failed to show an independent prognostic value for survival outcomes in this study unlike a previous study demonstrating the superior independent prognostic value of the GPS to IPI and NKPI in 164 patients with ENKTL [4]. These findings might be related with a relatively smaller number of patients in our study $(n=69)$ than the previous study. However, the strong correlation of serum CXCL13 with the GPS as well as high tumor burden such as stage and EBV DNA might influence their prognostic value in the multivariate analysis. On the other hand, in the subgroup analysis based on tumor burden, grouping by the serum level of CXCL13 and GPS discriminated patients with poor survival outcomes among those with stage I/II disease and/or with non-detectable EBV DNA (Figures 3 and 4). Following this, patients with elevated CXCL13 levels may be at a higher risk of treatment failure like patients with GPS 2. Our study results were from ENKTL patients that were registered in our prospective cohort study, and all patients were treated with non-anthracycline-based chemotherapy and/or concurrent chemoradiotherapy. Considering the majority of prior studies were retrospective in nature and included patients who were treated with anthracycline-based chemotherapy [1,28], our findings may be relevant to patients who have been treated with the current standard of care. The association of serum CXCL13 with GPS and survival outcomes of ENKTL patients might suggest the possibility of CXCL13 as a prognostic indicator and therapeutic target in patients with ENKTL. Therefore, future studies with larger patient populations should be warranted to confirm the prognostic value of serum CXCL13.

\footnotetext{
Abbreviations

GPS: Glasgow Prognostic Score; ENKTL: Extranodal NK/T-cell lymphoma; CXCL13: C-X-C motif ligand 13; CXCR5: C-X-C chemokine receptor 5; CRP: C-reactive protein; CCRT: Concurrent chemoradiotherapy; SMILE: Steroid,
}

methotrexate, ifosfamide, L-asparaginase, and etoposide; IPI: International Prognostic Index; NKPI: NK Prognostic Index; PFS: Progression-free survival; OS: Overall survival.

\section{Competing interests}

The authors declare that they have no competing interests.

\section{Authors' contributions}

SJK designed the project and wrote the manuscript. KJR performed the multiplex chemokine assay. WSK reviewed the manuscript and participated in its preparation. MH and YHK reviewed the pathology. SJK and WSK analyzed the data. All authors read and approved the final manuscript.

\section{Acknowledgements}

This study was supported by grants from the Samsung Biomedical Research Institute (SMO1150931) and the National Research Foundation of Korea's (NRF) Basic Science Research Program (NRF-2012R1A1A2008573), which is funded by the Ministry of Education, Science and Technology.

\section{Author details}

'Division of Hematology and Oncology, Department of Medicine, Samsung Medical Center, Sungkyunkwan University School of Medicine, Seoul, Korea. ${ }^{2}$ Samsung Biomedical Research Institute, Samsung Medical Center, Seoul, Korea. ${ }^{3}$ Department of Pathology, Kangnam Sacred Heart Hospital, Hallym University, Seoul, Korea. ${ }^{4}$ Department of Pathology, Samsung Medical Center, Sungkyunkwan University School of Medicine, Seoul, Korea. ${ }^{5}$ Department of Health Sciences and Technology, SAIHST, Sungkyunkwan University School of Medicine, Seoul, Korea.

Received: 30 January 2015 Accepted: 21 April 2015

Published online: 14 May 2015

\section{References}

1. Au WY, Weisenburger DD, Intragumtornchai T, Nakamura S, Kim WS, Sng I, et al. Clinical differences between nasal and extranasal natural killer/T-cell lymphoma: a study of 136 cases from the International Peripheral T-cell lymphoma Project. Blood. 2009;113:3931-7.

2. Kim SJ, Kim K, Kim BS, Kim CY, Suh C, Huh J, et al. Phase II trial of concurrent radiation and weekly cisplatin followed by VIPD chemotherapy in newly diagnosed, stage IE to IIE, nasal, extranodal NKT-cell lymphoma: Consortium for Improving Survival of Lymphoma study. J Clin Oncol. 2009;27:6027-32.

3. Yamaguchi M, Kwong YL, Kim WS, Maeda Y, Hashimoto C, Suh C, et al. Phase II study of SMILE chemotherapy for newly diagnosed stage IV relapsed, or refractory extranodal natural killer (NK)/T-cell lymphoma, nasal type: the NK-Cell Tumor Study Group study. J Clin Oncol. 2011;29:4410-6.

4. Li YJ, Jiang WQ, Huang JJ, Xia ZJ, Huang HQ, Li ZM. The Glasgow Prognostic Score (GPS) as a novel and significant predictor of extranodal natural killer/T-cell lymphoma, nasal type. Am J Hematol. 2013;88:394-9.

5. Forrest LM, McMillan DC, MCArdle CS, Angerson WJ, Dunlop DJ. Evaluation of cumulative prognostic scores based on the systemic inflammatory response in patients with inoperable non-small-cell lung cancer. Br J Cancer. 2003;89:1028-30.

6. Balkwill F, Mantovani A. Inflammation and cancer: back to Virchow? Lancet. 2001;357:539-45.

7. Mantovani A, Allavena P, Sica A, Balkwill F. Cancer-related inflammation. Nature. 2008:454:436-44.

8. Raman D, Sobolik-Delmaire T, Richmond A. Chemokines in health and disease. Exp Cell Res. 2011;317:575-89.

9. Murphy PM, Baggiolini M, Charo IF, Hebert CA, Horuk R, Matsushima K, et al. International union of pharmacology. XXII. Nomenclature for chemokine receptors. Pharmacol Rev. 2000;52:145-76.

10. Raman D, Baugher PJ, Thu YM, Richmond A. Role of chemokines in tumor growth. Cancer Lett. 2007;256:137-65.

11. Sarvaiya PJ, Guo D, Ulasov I, Gabikian P, Lesniak MS. Chemokines in tumor progression and metastasis. Oncotarget. 2013;4:2171-85.

12. Qi XW, Xia SH, Yin Y, Jin LF, Pu Y, Hua D, et al. Expression features of CXCR5 and its ligand, CXCL13 associated with poor prognosis of advanced colorectal cancer. Eur Rev Med Pharmacol Sci. 2014;18:1916-24.

13. Biswas S, Sengupta S, Roy Chowdhury S, Jana S, Mandal G, Mandal PK, et al. CXCL13-CXCR5 co-expression regulates epithelial to mesenchymal transition 
of breast cancer cells during lymph node metastasis. Breast Cancer Res Treat. 2014;143:265-76.

14. El-Haibi CP, Singh R, Sharma PK, Singh S, Lillard Jr JW. CXCL13 mediates prostate cancer cell proliferation through JNK signalling and invasion through ERK activation. Cell Prolif. 2011;44:311-9.

15. Zhu Z, Zhang X, Guo H, Fu L, Pan G, Sun Y. CXCL13-CXCR5 axis promotes the growth and invasion of colon cancer cells via PI3K/AKT pathway. Mol Cell Biochem. 2015:400:287-95.

16. Purdue MP, Hofmann JN, Kemp TJ, Chaturvedi AK, Lan Q, Park JH, et al. A prospective study of 67 serum immune and inflammation markers and risk of non-Hodgkin lymphoma. Blood. 2013;122:951-7.

17. Jeon YK, Park CH, Kim KY, Li YC, Kim J, Kim YA, et al. The heat-shock protein 90 inhibitor, geldanamycin, induces apoptotic cell death in Epstein-Barr virus-positive NK/T-cell lymphoma by Akt down-regulation. J Pathol. 2007:213:170-9.

18. Kim SJ, Yang DH, Kim JS, Kwak JY, Eom HS, Hong DS, et al. Concurrent chemoradiotherapy followed by L-asparaginase-containing chemotherapy, VIDL, for localized nasal extranodal NKTT cell lymphoma: CISL08-01 phase II study. Ann Hematol. 2014;93:1895-901.

19. Kwong YL, Kim WS, Lim ST, Kim SJ, Tang T, Tse E, et al. SMILE for natural killer/T-cell lymphoma: analysis of safety and efficacy from the Asia Lymphoma Study Group. Blood. 2012;120:2973-80.

20. Kim SJ, Park S, Kang ES, Choi JY, Lim Do H, Ko YH, et al. Induction treatment with SMILE and consolidation with autologous stem cell transplantation for newly diagnosed stage IV extranodal natural killer/T-cell lymphoma patients. Ann Hematol. 2015;94:71-8.

21. Forrest LM, McMillan DC, McArdle CS, Angerson WJ, Dunlop DJ. Comparison of an inflammation-based prognostic score (GPS) with performance status (ECOG) in patients receiving platinum-based chemotherapy for inoperable non-small-cell lung cancer. Br J Cancer. 2004;90:1704-6.

22. Kim HS, Kim KH, Kim KH, Chang MH, Ji SH, Lim Do H, et al. Whole blood Epstein-Barr virus DNA load as a diagnostic and prognostic surrogate: extranodal natural killer/T-cell lymphoma. Leuk Lymphoma. 2009;50:757-63.

23. Chim CS, Ma SY, Au WY, Choy C, Lie AK, Liang R, et al. Primary nasal natural killer cell lymphoma: long-term treatment outcome and relationship with the International Prognostic Index. Blood. 2004;103:216-21.

24. Lee J, Suh C, Park YH, Ko YH, Bang SM, Lee JH, et al. Extranodal natura killer T-cell lymphoma, nasal-type: a prognostic model from a retrospective multicenter study. J Clin Oncol. 2006;24:612-8.

25. Dupuis J, Boye K, Martin N, Copie-Bergman C, Plonquet A, Fabiani B, et al. Expression of CXCL13 by neoplastic cells in angioimmunoblastic T-cell lymphoma (AITL): a new diagnostic marker providing evidence that AITL derives from follicular helper T cells. Am J Surg Pathol. 2006;30:490-4.

26. Ebert LM, Schaerli P, Moser B. Chemokine-mediated control of T cell traffic in lymphoid and peripheral tissues. Mol Immunol. 2005;42:799-809.

27. Widney DP, Gui D, Popoviciu LM, Said JW, Breen EC, Huang X, et al. Expression and function of the chemokine, CXCL13, and its receptor CXCR5, in Aids-associated non-Hodgkin's lymphoma. AIDS Res Treat. 2010;2010:164586.

28. Mitrovic Z, Perry AM, Suzumiya J, Armitage JO, Au WY, Coiffier B, et al. The prognostic significance of lymphopenia in peripheral T-cell and natural killer/T-cell lymphomas: a study of 826 cases from the International Peripheral T-cell Lymphoma Project. Am J Hematol. 2012;87:790-4.

\section{Submit your next manuscript to BioMed Central and take full advantage of:}

- Convenient online submission

- Thorough peer review

- No space constraints or color figure charges

- Immediate publication on acceptance

- Inclusion in PubMed, CAS, Scopus and Google Scholar

- Research which is freely available for redistribution 